\title{
Measurement of Stretched Penile Length in Term Neonates at a Single Tertiary Care Centre of South India
}

\author{
Nitin Pingale ${ }^{1}$, Rajendra Nerli ${ }^{2,}$, ,Shridhar Ghagane ${ }^{3}$, Manas Sharma ${ }^{2}$, Shashank Patil ${ }^{2}$, \\ Pulkit Gupta $^{2}$ \\ ${ }^{1}$ Department of Urology, Bharati Vidyapeeth (Deemed-to-be-University), Pune, Maharashtra, India \\ ${ }^{2}$ Department of Urology, JN Medical College, KLE Academy of Higher Education \& Research, JNMC Campus, Belagavi, India \\ ${ }^{3}$ Urinary Biomarkers Research Centre, Department of Urology, KLES Dr. Prabhakar Kore Hospital \& Medical Research Centre, Nehru \\ Nagar, Belagavi, India
}

Email address:

rbnerli@gmail.com (R. Nerli)

${ }^{*}$ Corresponding author

\section{To cite this article:}

Nitin Pingale, Rajendra Nerli, Shridhar Ghagane, Manas Sharma, Shashank Patil, Pulkit Gupta. Measurement of Stretched Penile Length in Term Neonates at a Single Tertiary Care Centre of South India. International Journal of Clinical Urology. Vol. 5, No. 1, 2021, pp. 16-20. doi: $10.11648 /$ j.ijcu. 20210501.14

Received: September 10, 2020; Accepted: February 20, 2021; Published: March 4, 2021

\begin{abstract}
Evidence from several studies has shown that the penile length varies among different populations of different racial/ethnic groups. Size abnormalities of the newborn external genitalia may be a pointer to some endocrine and genetic disorders. In this study we have prospectively measured the stretched penile length of all newborns at our hospital in an attempt to define normative data for full term neonates of our region. All live male neonates born at our hospital were enrolled into the study. Stretched penile length was measured from the pubic ramus to the tip of the glans penis using a digital Vernier Calliper. The measurements were taken within 48 hours of birth. Two consecutive measurements were taken and the average was recorded as the final measurement. The mean stretched penile length was $2.63 \pm 0.35 \mathrm{~mm}$ and the mean diameter of glans was $1.04 \pm 0.09 \mathrm{~mm}$ respectively. The penile length significantly varied with the length (height) of the neonate as expressed in cms. The taller the neonate, longer was the penis. Similarly, the mean penile length and the diameter of the glans was significantly different $(\mathrm{p}<0.05)$ for different gestational age. The stretched penile length of neonates significantly correlates with the gestational age and the length of the neonate.
\end{abstract}

Keywords: STRETCHED Penile Length, Smoothed Percentile Values, Gestational Age, Neonate, Length of the Neonate

\section{Introduction}

The differentiation of external genitalia into the male sex begins in the 7th week of gestation and is completed by 16 17 weeks. [1] Between the 4th and 7th weeks, the mesodermal mesenchyme migrates to the cranial aspect of the cloacal membrane to form the genital tubercle. [1] Under the influence of androgens, in males the mesoderm of the genital tubercle enlarges to become the corpora cavernosa and glans penis. The endoderm tubularizes in a proximal to distal direction to form the penile urethra. The ectoderm develops into the penile skin and prepuce, which begins formation at 8 weeks. $[1,2]$ The proximal crus of the corpora cavernosa begin as separate structures spread apart under the ischium bilaterally and move medially under the pubis. The distal tips of the corpora cavernosa are capped by the glans penis, which is itself a continuation of the corpus spongiosum that surrounds the urethra.

Variations or abnormalities of the size of the penis in a newborn may point towards some endocrine and/or genetic disorders. One such abnormality that affects the penile length is micropenis, which is seen in congenital hypopituitarism, Noonan and Robinow syndromes [3, 4] and some chromosomal abnormalities such as Prader-Willi. [5] There exists evidence that the penile length varies among different racial/ethnic groups. [3-6] This makes it necessary to establish standard values for penile sizes in normal, healthy, 
full-term neonates in each country and in its different regions. In this study we prospectively measured the stretched penile length of all newborns at our hospital in an attempt to define normative data for full term neonates of our region.

\section{Materials \& Methods}

All live male neonates born at our hospital during the period 01-01-2017 to 31-7-2017 were enrolled. Written informed consent was obtained from the parents of all the included neonates. This study was conducted with the consent from the Institutional/University ethical committee KLESKFIEC/2016/015.

Inclusion and Exclusion criteria: All normal, term neonates with gestational age between 28 and 42 weeks were included in the study. Gestational age was calculated from the $1^{\text {st }}$ day of the last menstrual period of the mother. Preterm neonates, low birth weight neonates, and those with gross congenital anomalies were excluded from the study.

Examination and Measurements: All examinations were performed in a warm and comfortable room by the same researcher and a trained neonatal nurse. All neonates were examined in a supine position with both legs in a flexed position. Stretched penile length was measured from the pubic ramus to the tip of the glans penis using a digital Vernier Calliper. The location of the tip of the glans penis was located by palpation. Similarly, the glanular diameter was measured using the same Vernier Calliper (Figure 1). The measurements were taken within 48 hours of birth. Two consecutive measurements were taken and the average was recorded as the final measurement.

Statistical Analysis: Results were presented as mean \pm SD for quantitative variables and were summarized by frequency (percentage) for categorical variables. The correlation of variables was tested by correlation analysis and backward regression analysis was used for prediction penile length and circumference. For the statistical analysis, the statistical software SPSS version 16.0 for windows (SPSS Inc., Chicago, IL, USA) was used. $P$ values of 0.05 or less were considered statistically significant.

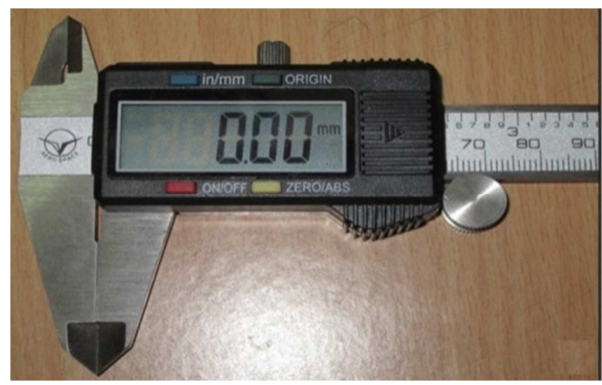

Figure 1. Vernier caliper.

\section{Results}

During the 7 months' study period a total of 500 male neonates were examined for penile length as well as diameter of the glans. All these neonates were term births with no obvious visible genital or other congenital anomalies. The mean penile length and diameter of glans was $2.63 \pm 0.35 \mathrm{~mm}$ and $1.04 \pm 0.09$ $\mathrm{mm}$ respectively. The gestational age of the neonates ranged from $29-41$ weeks (Table 1). The mean penile length and the diameter of the glans was significantly different $(\mathrm{p}<0.05)$ for different gestational age (Figure 2 and Figure 3).

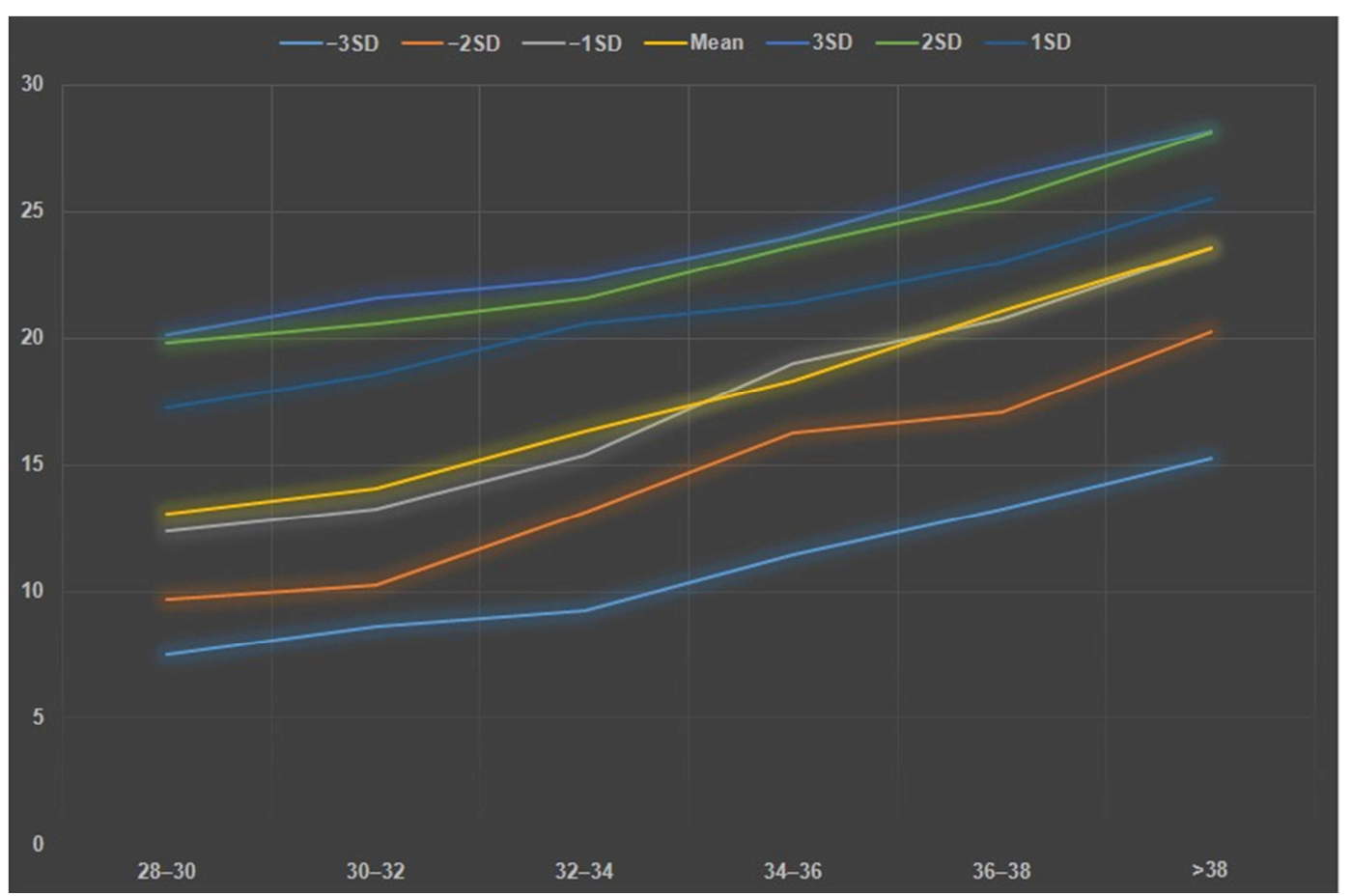

Figure 2. Mean and SD of penile length based on different gestational age. 




Figure 3. Mean and SD of diameter of the glans based on different gestational age.

The penile length significantly varied with the length (height) of the neonate expressed in cms (Table 2). The taller the neonate, longer was the penis. The birth weight of the neonate did not correlate with the length of the penis in the neonate (Table 3). The mother's age had a significant influence on the neonates' penile length (Table 4).

Table 1. Correlation between Gestational Age, Penile length and Glans Diameter.

\begin{tabular}{lllll}
\hline \multirow{2}{*}{ Gestational Age in Weeks } & Parameter & & & \\
\cline { 2 - 5 } & Mean Penile Length $(\mathbf{c m})$ & p-value & Mean Glans Diameter (cm) & p-value \\
\hline$\leq 31(10)$ & $1.59 \pm 0.32$ & $0.0008^{*}$ & $0.65 \pm 0.29$ & 0.0229 \\
$32-35(43)$ & $1.96 \pm 0.09$ & $0.0001^{*}$ & $0.90 \pm 0.04$ & $0.0001^{*}$ \\
$36-39(332)$ & $2.61 \pm 0.18$ & $0.0001^{*}$ & $1.04 \pm 0.02$ & $0.0001^{*}$ \\
$\geq 40(115)$ & $3.02 \pm 0.11$ & $0.0001^{*}$ & $1.14 \pm 0.04$ & $0.0001^{*}$ \\
\hline
\end{tabular}

*The result is significant at $\mathrm{p}<0.05$.

Table 2. Correlation of Baby length (cm) with Penile Length and Glans diameter

\begin{tabular}{llll}
\hline \multirow{2}{*}{ Baby Length (cm) } & Parameter & & \\
\cline { 2 - 4 } & Mean Penile Length $(\mathbf{c m})$ & p-value & Mean Glans Diameter (cm) \\
\hline$\leq 41(30)$ & $1.79 \pm 0.24$ & $0.0001^{*}$ & $0.80 \pm 0.20$ \\
$41-45(80)$ & $2.23 \pm 0.15$ & $0.0001^{*}$ & $0.98 \pm 0.04$ \\
$46-50(344)$ & $2.73 \pm 0.17$ & $0.0001^{*}$ & $1.06 \pm 0.03$ \\
$\geq 50(46)$ & $3.11 \pm 0.13$ & $0.0001^{*}$ & $0.0001^{*}$ \\
\hline
\end{tabular}

*The result is significant at $\mathrm{p}<0.05$.

Table 3. Correlation of Birth Weight (Kg) with Penile Length and Glans diameter.

\begin{tabular}{lllll}
\hline \multirow{2}{*}{ Birth weight in Kg. } & Parameter & & & \\
\cline { 2 - 5 } & Mean Penile Length (cm) & p-value & Mean Glans Diameter (cm) & p-value \\
\hline$\leq 1.9(46)$ & $2.65 \pm 0.35$ & 0.4945 & $1.05 \pm 0.07$ & 0.5748 \\
$2-2.4(97)$ & $2.66 \pm 0.32$ & 0.4365 & $1.05 \pm 0.07$ & 0.2919 \\
$2.5-2.9(212)$ & $2.63 \pm 0.33$ & 0.7799 & $1.04 \pm 0.09$ & 0.3055 \\
$\geq 3(145)$ & $2.60 \pm 0.39$ & 0.5721 & $1.03 \pm 0.11$ & 0.1603 \\
\hline
\end{tabular}


Table 4. Correlation of Mothers age with Penile Length and Glans Diameter.

\begin{tabular}{lllll}
\hline \multirow{2}{*}{ Mothers Age (years) } & Parameter & & & \\
\cline { 2 - 5 } & Mean Penile Length $(\mathbf{c m})$ & p-value & Mean Glans Diameter (cm) & p-value \\
\hline $18-24(332)$ & $2.45 \pm 0.30$ & $0.0001^{*}$ & $1.00 \pm 0.09$ & $0.0001^{*}$ \\
$25-29(132)$ & $2.92 \pm 0.07$ & $0.0001^{*}$ & $1.10 \pm 0.02$ & $0.0001^{*}$ \\
$\geq 30(36)$ & $3.14 \pm 0.14$ & $0.0001^{*}$ & $1.20 \pm 0.01$ & $0.0024^{*}$ \\
\hline
\end{tabular}

*The result is significant at $\mathrm{p}<0.05$.

The mother's weight (Table 5), height (Table 6), number of pregnancies (Table 7), and pregnancy associated hypertension (Table 8) did not significantly affect the penile length of the neonate.

Table 5. Correlation of Mother's Weight with Penile Length and Glans Diameter.

\begin{tabular}{lllll}
\hline \multirow{2}{*}{ Mother's weight (Kg) } & Parameter & & & \\
\cline { 2 - 5 } & Mean Penile Length (cm) & p-value & Mean Glans Diameter (cm) & p-value \\
\hline$\leq 50(144)$ & $2.62 \pm 0.35$ & 0.6814 & $1.05 \pm 0.08$ & 0.7643 \\
$51-60(270)$ & $2.65 \pm 0.32$ & 0.1672 & $1.05 \pm 0.07$ & 0.1492 \\
$61-70(66)$ & $2.55 \pm 0.44$ & 0.1868 & $1.01 \pm 0.18$ & 0.3788 \\
$\geq 71(20)$ & $2.62 \pm 0.37$ & 0.2871 & $1.05 \pm 0.08$ & 0.3275 \\
\hline
\end{tabular}

Table 6. Correlation of Mother's Height (Kg) with Penile Length and Glans Diameter.

\begin{tabular}{lllll}
\hline \multirow{2}{*}{ Mother's Height $(\mathbf{c m})$} & Parameter & & & \\
\cline { 2 - 5 } & Mean Penile Length $(\mathbf{c m})$ & p-value & Mean Glans Diameter $(\mathbf{c m})$ & p-value \\
\hline$\leq 150(143)$ & $2.65 \pm 0.32$ & 0.0688 & $1.05 \pm 0.07$ & 0.0482 \\
$151-160(335)$ & $2.64 \pm 0.34$ & 0.2906 & $1.05 \pm 0.09$ & 0.9880 \\
$\geq 161(22)$ & $2.30 \pm 0.52$ & 0.6789 & $0.93 \pm 0.22$ & 0.6835 \\
\hline
\end{tabular}

Table 7. Correlation of Number of Pregnancies with Penile Length and Glans Diameter.

\begin{tabular}{lll}
\hline \multirow{2}{*}{ Number of Pregnancies } & Parameter & \\
\cline { 2 - 3 } & Mean Penile Length $\mathbf{( c m )}$ & Mean Glans Diameter (cm) \\
\hline $1(233)$ & $2.62 \pm 2.6$ & $1.04 \pm 0.09$ \\
$2(193)$ & $2.65 \pm 0.35$ & $1.05 \pm 0.10$ \\
$3(54)$ & $2.55 \pm 0.38$ & $1.03 \pm 0.08$ \\
$\geq 4(20)$ & $2.61 \pm 0.32$ & $1.04 \pm 0.06$ \\
\hline
\end{tabular}

Table 8. Correlation of Pregnancy Induced Hypertension with Penile Length and Glans Diameter.

\begin{tabular}{lll}
\hline Comorbidity & Parameter & \\
\hline Pregnancy Induced Hypertension & Mean Penile Length (cm) & Mean Glans Diameter (cm) \\
\hline YES (70) & $2.56 \pm 0.35$ & $1.03 \pm 0.07$ \\
NO (430) & $2.64 \pm 0.35$ & $1.05 \pm 0.10$ \\
& $\mathrm{p}=0.0768$ & $\mathrm{p}=0.1081$ \\
\hline
\end{tabular}

\section{Discussion}

Physical examination of a neonate which includes the inspection of the genital area is a very important part of the assessment of a new-born. Measurement of the penile size is considered important as it is an indicator of the hypothalamic pituitary axis. Abnormalities in the penile size may be due to inadequate androgen exposure during foetal development. [7] Penile measurement also contributes towards the diagnosis of the underlying genetic disorders [8] and is important in procedures, such as circumcision, as well. [9]

Micropenis has been defined as a small sized penis that is 2.5 SDs below the mean penile length without epispadias or hypospadias. [10] The accuracy of penile length measurement and cut-off for the definition of micropenis is of great importance, which is commonly missed in early physical examination of the new-born. Stretched penile length (SPL) is commonly available on nomograms, based on gestational age, weight, and height. [11] Penile length (PL) values also vary depending on the gestational age, prematurity of the newborn [12], as well as in different ethnicities. [13] Measurements of PL in neonates will help in developing the correct nomograms which represent the local populations.

We have used the digital vernier caliper in this study, to measure the penile length as well as the diameter of the glans. The accurate measurement of penile length is important in children especially with abnormal genital development, e.g. micropenis, microphallus, buried penis and webbed scrotum. 
[14-16] Ozbey et al [16] described a simple and effective method for measuring penile length in neonates and infants. A $10-\mathrm{mL}$ disposable syringe was used in a modified fashion by removing the needle-bearing end and introducing the piston into the cut end. The flanged end was then placed over the penis to be measured, firmly pressed onto the pubis and the piston partially withdrawn, causing suction. This drew the penis into the injector, partly erect, and excluded the prepubic fat. The length of the penis was then read from the attached scale when the suction was optimal.

Chikani et al [17] reported on the normative values of stretched penile length in apparently healthy term Igbo newborn males in South eastern Nigeria and its relationship with gestational age, birth weight and birth length. The stretched penile length was measured in eight hundred and eleven apparently healthy term male neonates within the first $72 \mathrm{~h}$ of life. The mean stretched penile length of term newborns was $3.46 \pm 0.44 \mathrm{~cm}$. The lower and upper limits $( \pm 2.5$ SD) were $2.36-4.56 \mathrm{~cm}$. Stretched penile length correlated positively with birth length and birth weight $(r=0.343$, $\mathrm{p}=0.001 ; \mathrm{r}=0.229, \mathrm{p}=0.001$ ).

Soheilipour et al [18] reported on stretched penile length (SPL) values and cut-off level of micropenis in term and preterm Iranian neonates. Among a total of 587 neonates, 203 neonates were born term and 384 preterm. Mean \pm SD of their SPL was $22.48 \pm 3.34 \mathrm{~mm} ; 25.92 \pm 1.54 \mathrm{~mm}$ in term and $20.66 \pm 2.50 \mathrm{~mm}$ in preterm infants $(P=0.001)$.

\section{Conclusion}

The authors concluded that The SPL in male neonates correlated with gestational age and birth weight. Our study too showed that the SPL significantly correlated to the gestational age, but did not correlate with birth weight. Our study clearly shows an association of SPL with anthropometric variables of new-borns and that SPL can be very variable in each population; thus, it is essential to refer to the normal value that is defined for a specific population and the results of such studies can help physicians and researchers in this respect.

There are several limitations of our study including the small number of neonates examined over a short period of time. Our hospital being a private hospital, the patients attending our hospital usually come from financially middle class, hence a very selective population. There could be several factors that we have not taken into consideration, which could have had a bearing on our study. To conclude our study has clearly shown that the stretched penile of neonates is significantly associated with the gestational age and the length of the neonate.

\section{Conflict of Interest}

All the authors do not have any possible conflicts of interest.

\section{References}

[1] Yiee JH and Baskin LS. Penile Embryology and Anatomy. The Scientific World Journal 2010; 10: 1174-1179.

[2] Moore, K. and Persaud, T. Before We Are Born: Essentials of Embryology and Birth Defects. WB Saunders, Philadelphia. 1998.

[3] Assawabumrungkul S, Pichetsin K. Stretched penile length of Thai term newborn. $R$ Thai Air Force Med Gazette 2010; 56: $3-4$.

[4] Fok TF, Hon KL, So FK. Normative data of penile length for term Chinese newborns. Biol Neonate 2005; 87: 242-5.

[5] Ting IH, Wu LL. Penile length of term newborn infants in multiracial Malaysia. Singapore Med J 2009; 50: 817-20.

[6] Lian WB, Lee WR, Ho LY. Penile length of newborns in Singapore. J Pediatr Endocrinol Metab 2000; 13: 55-62.

[7] Hines M, Constantinescu M, Spencer D. Early androgen exposure and human gender development. Biol Sex Di er 2015; $6(1): 3$.

[8] Menon PS, Khatwa UA. The child with micropenis. Indian $J$ Pediatr 2000; 67 (6): 455-60.

[9] Park JK, Doo AR, Kim JH, et al. Prospective investigation of penile length with newborn male circumcision and second to fourth digit ratio. Can Urol Assoc J 2016; 10 (9-10): E296.

[10] Ludwig G. Micropenis and apparent micropenis - a diagnostic and therapeutic challenge. Andrologia 1999; 31 (S1): 27-30.

[11] Ponchietti R, Mondaini N, Bonafè M, et al. Penile length and circumference: a study on 3,300 young Italian males. Eur Urol 2001; 39 (2): 183-6.

[12] Tuladhar R, Davis P, Batch J, Doyle L. Establishment of a normal range of penile length in preterm infants. $J$ Paediatr Child Health 1998; 34 (5): 471-3.

[13] Kutlu AO. Normative data for penile length in Turkish newborns. J Clin Res Pediatr Endocrinol 2010; 2 (3): 107-10.

[14] Nerli RB, Koura A, Prabha V, Reddy M. Comparison of topical versus parenteral testosterone in children with microphallic hypospadias. Pediatric surgery international. 2009; 25 (1): 57-9.

[15] Nerli RB, Guntaka AK, Patne PB, Hiremath MB. Penile growth in response to hormone treatment in children with micropenis. Indian journal of urology: 2013; 29 (4): 288.

[16] Ozbey H, Temiz A and Salman T. A simple method for measuring penile length in newborns and infants. BJU Int 1999; 84: 1093-94.

[17] Chikani UN, Chinawa JM, Ikefuna AN, Ibekwe MU. Stretched penile length of healthy term neonates: normative values among Igbo babies in Southeastern Nigeria. J Trop Pediatr 2015; 61 (1): 69-73.

[18] Soheilipour F, Rohani F, Dehkordi EH, et al. The Nomogram of Penile Length and Circumference in Iranian Term and Preterm Neonates. Front. Endocrinol. 2018; 9: 126. 